\title{
Effects of leaf removal on yield components in sunflower
}

\author{
A. S. Rodrigues Pereira \\ Unilever Research Duiven, Zevenaar, the Netherlands
}

Accepted: 25 July 1977

Key words: leaf area, yield components, sunflower

\section{Summary}

In a study of the relationship between leaf apparatus and yield in sunflower, the Rumanian hybrid HS 18 and the French hybrid INRA 4701 were subjected to a variety of leaf removal treatments. These treatments differed both in the number and in the position of the leaves removed. The leaves were removed one at a time during the vegetative period in one series and all at once shortly before flowering in another.

The effects of the various treatments on final plant height, size of the head, seed setting and different aspects of yield were determined.

INRA 4701 was more sensitive to leaf removal in terms of plant height and head size, whereas seed and oil yield were affected more in HS 18.

Seed setting in the centre of the inflorescence was better in INRA 4701 than in HS 18 for all treatments. Relative to the controls, however, the effect of leaf removal was more injurious to seed setting in INRA 4701.

\section{Introduction}

Interest in the sunflower amongst Dutch agronomists is steadily increasing (Dantuma \& Faure, 1973). Although the sunflower is not yet grown commercially in this country, physiological investigations on the crop have gained new impetus.

Helianthus annuus L., particularly in the seedling stage, has long been used for plant physiological investigations; in fact, for the study of plant growth, it has the status of a classic experimental plant. Attention is now being shifted to the whole adult plant and to the study of processes and environmental conditions determining the yield of organic mass, seed and oil. The relationship between the leaf apparatus and yield of the individual plant is basic to all such investigations. For that reason we decided to investigate the response of yield components to a variety of treatments in which either the number or the area of the leaves is decreased.

Artificial defoliation relates to the practical situation in that leaf area in the field is likely to be reduced as a result of senescence or factors like drought, hail, insects and disease. As usually applied, however, artificial defoliation has two weak points. 
Firstly few defoliation studies involve exact measurements of leaf areas and mostly only the leaves or groups of leaves that have been removed or left are specified. Experiments where leaf measurements have been included are those on maize by Allison \& Watson (1966) and on sorghum by Stickler \& Pauli (1961). Secondly the leaves are often removed only at flowering or a couple of days beforehand. This is done on the grounds (Allison \& Watson, 1966) that the photosynthetic production of the vegetative period contributes only little to the seed growth. This consideration neglects the fact that any reduction of the leaf area at an earlier stage not only influences the eventual size and form of the plant as such, but also its resources for seed production and thus, indirectly, the yield.

The investigations described here incorporate both leaf area measurements and 'early' defoliation. On the basis of a fairly extensive set of complementary defoliation treatments we have tried to quantify some yield - leaf area relationships in sunflower and, at the same time to assess the relative sensitivity of two hybrids to injuries inflicted to the leaf apparatus either at mid-season or at a late stage of vegetative development.

\section{Material and methods}

\section{Material}

The experiment was conducted in the summer of 1974 with the French hybrid INRA 4701 and the Rumanian hybrid HS 18, which is both shorter and a little earlier. Each of the two main plots was divided into two subplots, one for the early defoliations and one for the late defoliations. Each subplot was subdivided into two rows of 10 sub-subplots for the 20 defoliation treatments. Each sub-subplot consisted of 2 rows of plants with untreated border rows, but without border plants between the treatments.

The most injurious treatments were applied to the plants in the east of the subplots: treatments became progressively milder from east to west. Distance between rows was $1 \mathrm{~m}$, plant distance within rows was $75 \mathrm{~cm}$ (density 1.33 plants $/ \mathrm{m}^{2}$ ). The plants were sown in the third week of April. During most of the experiment the weather was extremely bad: it was a very wet summer (Faure, 1975). From each sub-subplot 10 plants were harvested in the second week of September, and the measurements on these were pooled.

\section{Defoliation scheme}

The average number of leaves per plant was 27 in INRA 4701 and 22 in HS 18. 'Early' defoliations were performed during the vegetative period; 'late' defoliations shortly before flowering. In the early treatments leaves were removed when they were $7-8 \mathrm{~cm}$ long.

The defoliation scheme is shown in Fig. 1. The treatments can be divided into the following 5 groups.

- In the first group (a-d) the number of leaves left on the plant increased by 5 from the bottom upwards.

- In the second group (e-h) the number of leaves removed increased by 5 from 


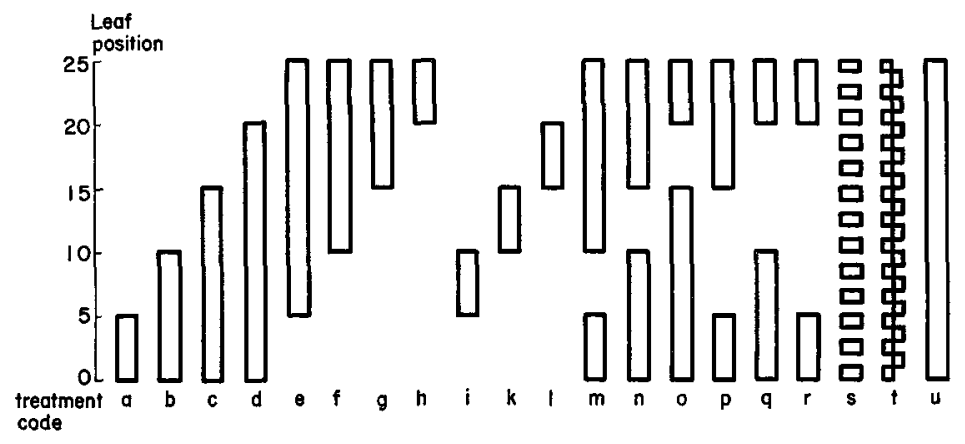

Fig. 1. Experimental design: vertical bars indicate the positions of the leaves remaining after defoliation.

$(\mathrm{a} \rightarrow \mathrm{h})$ increasing proportion of youngest leaves;

$(\mathrm{i} \rightarrow 1)$ increasing height of 5 remaining leaves;

$(\mathrm{m} \rightarrow \mathrm{o})$ increasing height 5 missing leaves;

$(\mathrm{p} \rightarrow \mathrm{r})$ combinations of treatments $\mathrm{m}, \mathrm{n}$ and $\mathrm{o}$;

(s) removal of even leaves $\} 50 \%$ reduction of foliage;

(u) untreated control.

the bottom upwards (in the early treatments defoliation was started after the plants had produced $20,15,10$ or 5 leaves respectively; the oldest leaf was then removed each time the next new leaf had grown to about $7 \mathrm{~cm}$ ).

- In the third group (i-1) plants of each treatment have only 5 leaves but at different heights on the stem.

- In the fourth group (m-r) the treatments complement those of the third group or combinations of these. Five successive leaves were removed either in single sets or in twos or threes. In the third and fourth groups early defoliations were carried out in a manner analogous to that in the second group.

- In the fifth group the foliage was reduced by $50 \%$ either by removing evennumbered leaves only ( $s$ ) or by cutting off half of each leaf alongside the midrib ( $t$ ).

Non-defoliated controls were coded ' $u$ '.

An indefinite number of the lower leaves dropped off at various times during the life-time of most of the plants. As a result similarities arose between treatments $b$ and $\mathrm{i}, \mathrm{f}$ and $\mathrm{m}$, $\mathrm{g}$ and $\mathrm{p}$, etc., which may be reflected in the results.

\section{Measurements}

The area of a leaf was determined by multiplying the product of its length and maximum width by the leaf-area coefficient. This coefficient was determined for both INRA 4701 and HS 18 for each leaf position and for different plant densities (Rodrigues Pereira, 1977). In both hybrids its value is a function of leaf position, whereas in INRA 4701 it is also influenced by plant density. The formulae used for the determination of the leaf-area coefficient (LAC) were:

\section{$\mathrm{LAC}_{\text {INRA }} 4701$}




\section{$\mathrm{LAC}_{\mathrm{HS} 18}$}

in which $\mathrm{p}=$ leaf position. The INRA 4701 formula corresponds with a plant density of 5 plants $/ \mathrm{m}^{2}$, the lowest density tested.

Plant height and leaf dimensions of the 10 plants of each treatment to be harvested were recorded during the second and third week of flowering. The measurements were carried out in the early and late defoliation series of INRA 4701 and in the early series of HS 18. The late series of HS 18 was not measured as results with INRA 4701 showed that leaves and stem grow only little after the beginning of flowering.

The diameters of the inflorescence and of its central part, where setting is poor, were determined at harvest time. All other yield parameters (seed yield, grain weight, oil content, etc.) were determined after the heads had been threshed and the seed had been dried to a moisture content of about $6 \%$.

\section{Results}

Because of the very wet and cold summer, plants were heavily attacked by fungi, particularly Botrytis cinera L. and Sclerotinia sclerotiorum (Lib.) de Bary. Plants with their top leaves intact were less severely attacked than plants from which these had been removed.

The results of treatments a-r, for which both leaf position and total leaf area are important, will be discussed separately from those of treatments $s-t$, for which the factor of leaf position is eliminated. For ease of comparison most of the data were converted to percentages of those of the untreated control.

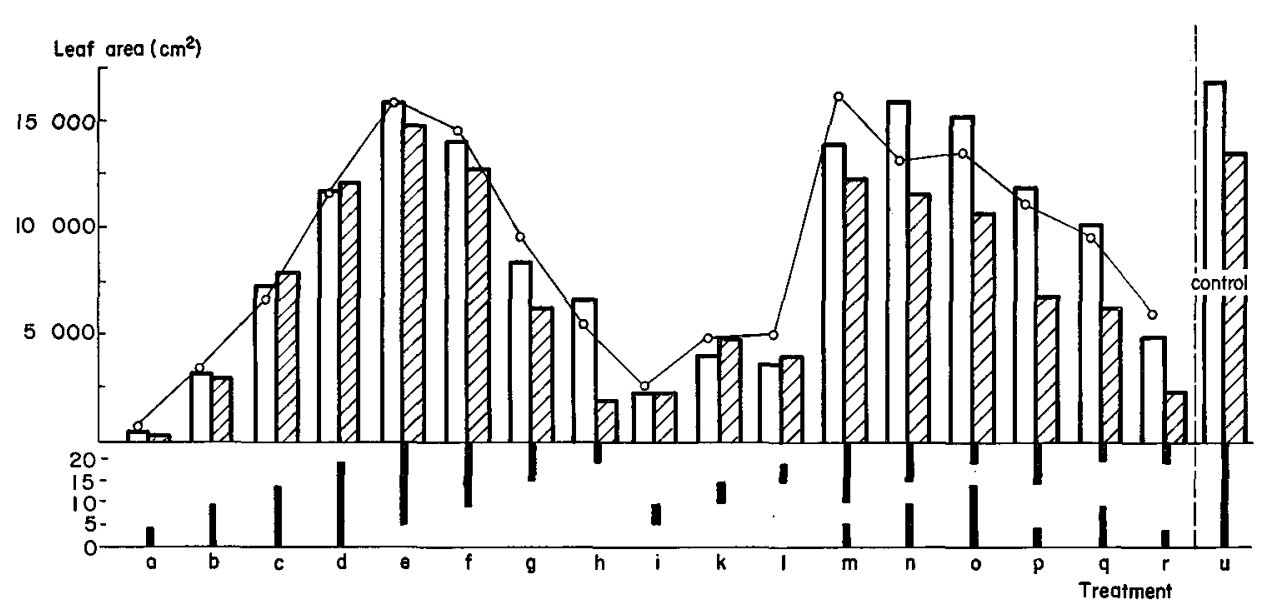

Fig. 2. Leaf area for the various defoliation treatments. White bars: INRA 4701 early; open dots: INRA 4701 late; hatched bars: HS 18. 


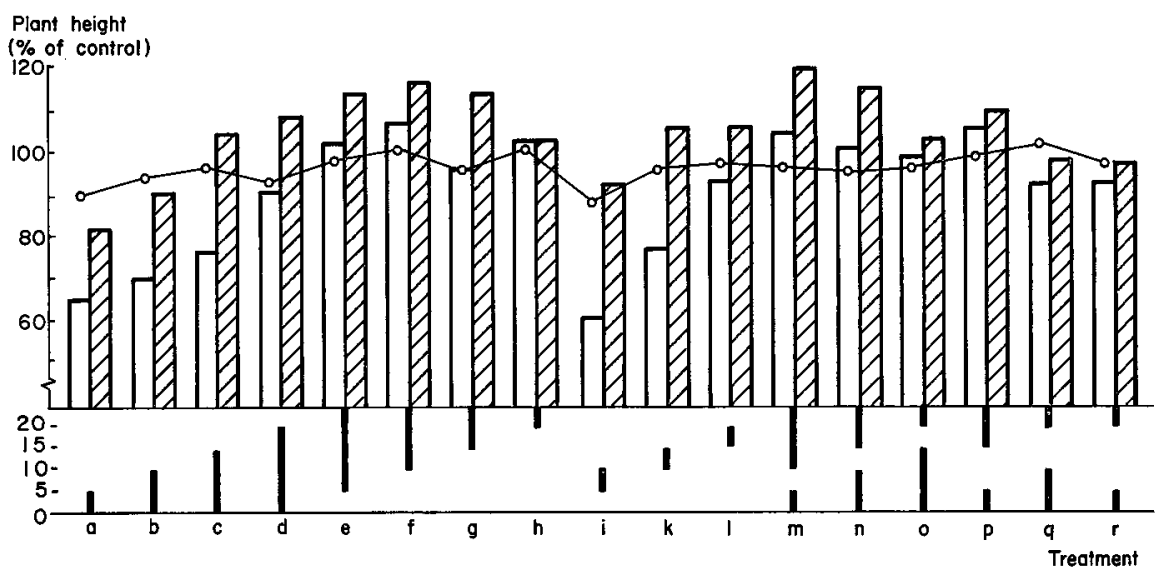

Fig. 3. Effect of defoliation on plant height, as percentage of control (for legend see Fig. 2).

\section{Growth}

Leaf area (Fig. 2). There was little difference between the total areas of the remaining leaves on early- and late-treated plants, or between these and the areas of the corresponding groups of leaves of the control plants. The leaf areas per plant, averaged over the 17 treatments a-r (and over the corresponding leaves of the controls) were as follows (in $\mathrm{cm}^{2}$ ):

$\begin{array}{llcl} & \text { early } & \text { late } & \text { control } \\ \text { INRA 4701 } & 8900 & 8950 & 8400 \\ \text { HS 18 } & 7100 & \text { not determined } & 6500\end{array}$

The differences between treatments and control is consistent though not significant. It suggests a slight enlargement of the leaves remaining after partial defoliation, whether early or late. The same was observed in a preliminary experiment with early defoliations only (Rodrigues Pereira, 1974).

Plant height (Fig. 3). Except for three treatments, the late leaf removals in INRA 4701 gave shorter plants than the controls; evidently at the time of defoliation (i.e. 3 or 4 days before anthesis) the stems had not yet attained their full size and further elongation could still be checked. Comparison of the early treatments shows that the relative decrease in stem elongation was more marked in INRA 4701 than in HS 18. In INRA 4701 plant height was decreased more than $20 \%$ by early removal of all leaves younger than number 15 (treatments a, b, c, i, k). In HS 18 early removal of leaves older than number 15 (treatments $e, f, g, m, n$ ) gave increases of more than $10 \%$ over the control: none of the treatments caused a decrease of as much as $20 \%$ and only 2 caused a decrease of more than $10 \%$. 


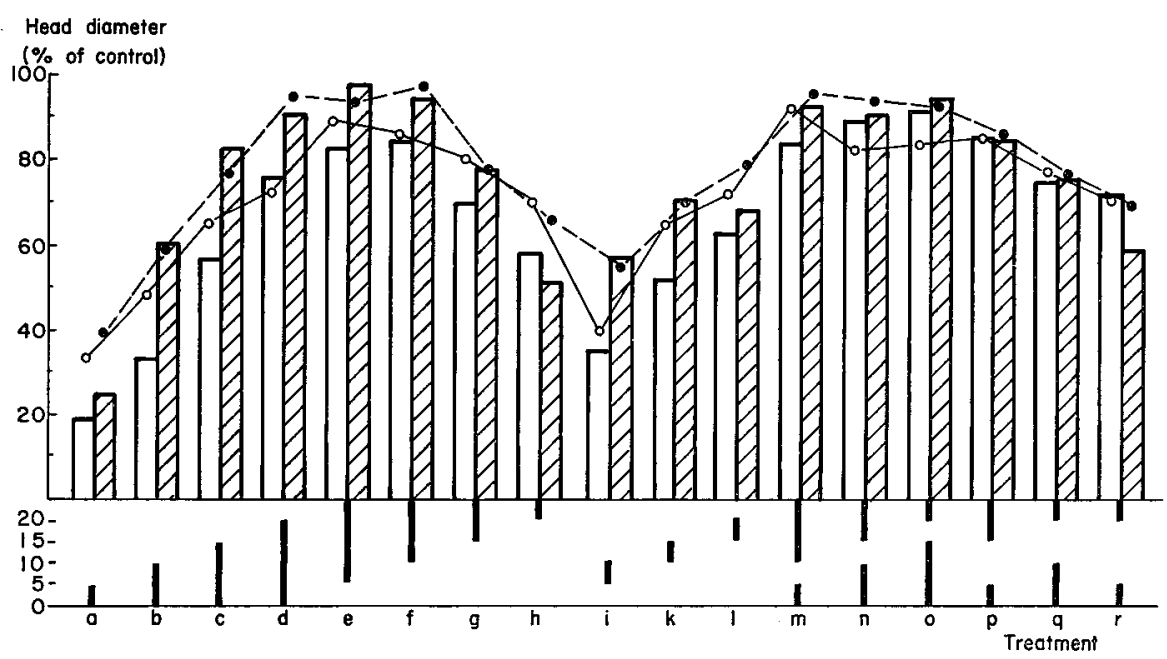

Fig. 4. Effect of defoliation on diameter of inflorescence, as percentage of control. Open dots: INRA 4701 late; white bars: INRA 4701 early; black dots: HS 18 late; hatched bars: HS 18 early.

Head size (Fig. 4). Reduction in diameter of the inflorescence in the late treatments equalled that in the early ones. This seems paradoxical because the number of florets is fixed shortly before anthesis. A reduction in head diameter by late defoliation cannot therefore be ascribed to a decrease in the number of florets that have been initiated and must be due to a failure of the florets to develop or to the unability of the plant to fill the seeds after fertilization. The effects of the various treatments on diameter parallel those on 1000 -grain weight, i.e. seed size. This yield parameter was determined only for full seeds; it takes no account of the area of faulty setting in the centre of the inflorescence. The effect of the late treatments on head diameter can therefore be described in terms of both an increase of the central area of tiny, empty seeds and of a decrease in grain weight.

In the early treatments a third factor is involved as well, namely the vitality of the plant as such which is repeatedly being weakened by the successive defoliations. Although HS 18 inflorescences are larger than those of INRA $4701(374 \mathrm{~mm}$ as against $358 \mathrm{~mm}$ ) the effect of defoliation is less severe in this hybrid.

\section{Yield}

Area of poor setting. In Fig. 5 areas of the central part of the head are presented as percentages of the total head area. In a previous experiment (Rodrigues Pereira, 1974) we found that this value is positively correlated with the number of leafless internodes below the inflorescence. This was confirmed for the series $u-d-c-b-a$ and $\mathrm{h}-\mathrm{l}-\mathrm{k}-\mathrm{i}-\mathrm{a}$. Averages of the aforementioned percentages, i.e. (centre area/head area) $\times 100$ for the treatments a-r were as follows: 


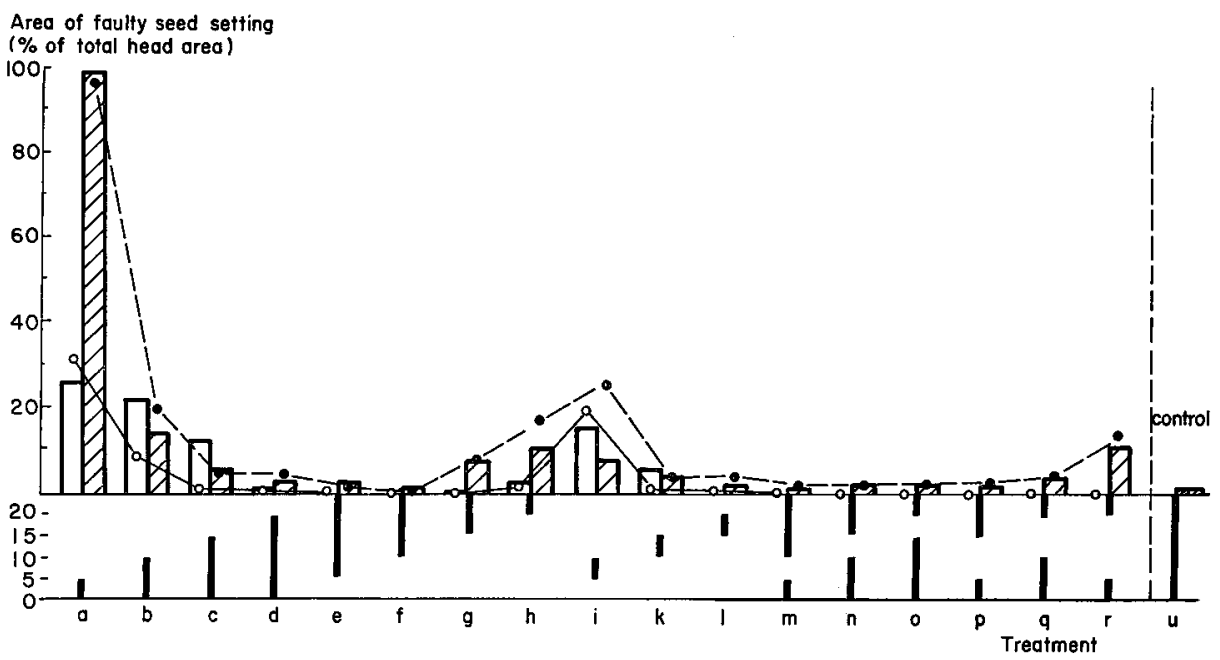

Fig. 5. Effect of defoliation on seed setting, expressed as the area of faulty seed setting as a percentage of total head area (for legend, see Fig. 4).

$\begin{array}{llrl} & \text { early } & \text { late } & \text { control } \\ \text { INRA 4701 } & 4.62 & 3.49 & 0.06 \\ \text { HS 18 } & 9.02 & 11.71 & 0.72\end{array}$

In all treatments seed setting in the centre was consistently poorer for HS 18 than for INRA 4701, possibly because this hybrid is less well adapted to the atlantic climate.

Seed yield, oil content and oil yield. As far as seed and oil yield are concerned, HS 18 plants were more sensitive to partial defoliations than INRA 4701 plants. The early treatments had a greater effect than the late ones.

Yield increased in the series a-i-k-l-h and decreased in the series $m-n-o-p-q-r$. This shows that, almost regardless of size, the younger leaves at all levels are more productive than the older ones. We have seen that when part of the foliage is removed, the remaining leaves get an extra growth impulse. Hence the extent to which yield $(Y)$ is reduced by the removal of a certain group of leaves (e.g. for leaves 1-5: $Y_{\mathrm{u}}-\mathrm{Y}_{\mathrm{e}}$ ) could be less than the yield of plants on which the same leaves are the only ones present (in this case $\mathrm{Y}_{\mathrm{a}}$ ). We have investigated this by comparing the yields in treatments $a, i, k, 1$ and $h$ with the differences in yield between the untreated control $(\mathrm{u})$ and $\mathrm{e}, \mathrm{m}, \mathrm{n}$, o and $\mathrm{d}$ respectively. We could, however, find no evidence for extra productivity of leaves remaining after partial defoliation.

The effects of the various defoliation treatments on seed yield are shown in Fig. 6.

Oil content of the seeds in the untreated controls was $45.1 \%$ in HS 18 and $37.1 \%$ in INRA 4701 on a dry weight basis. Within all treatments, however, oil content varied considerably and it was almost impossible to establish correlations 


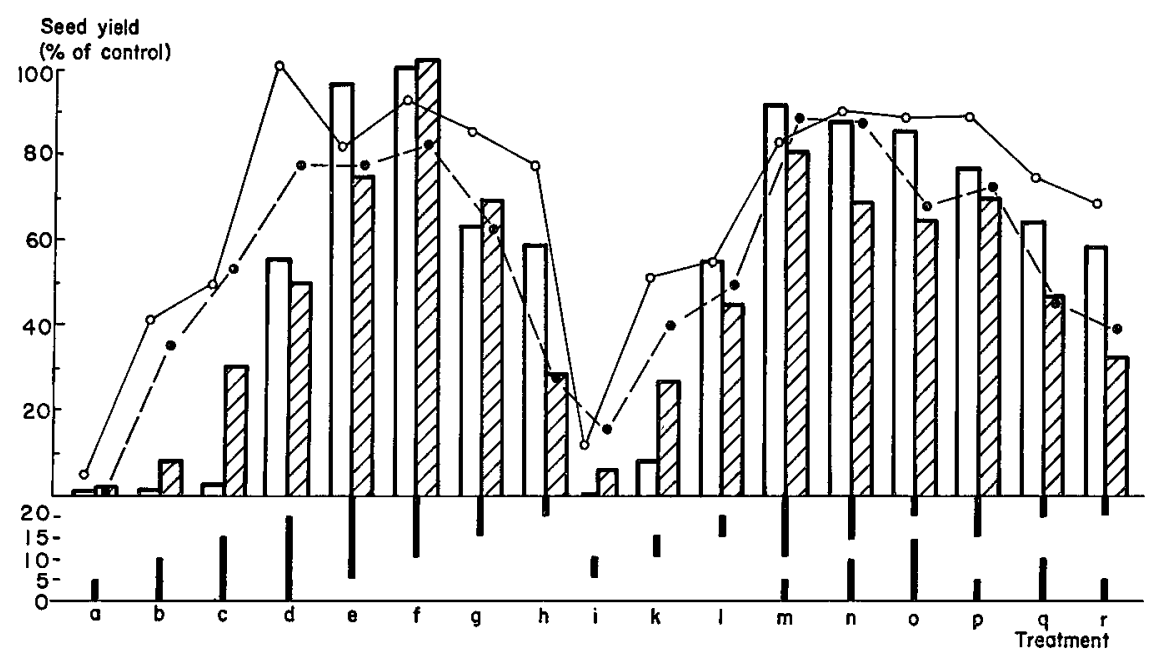

Fig. 6. Effect of defoliation on seed yield, as percentage of control (for legend, see Fig. 4).

with particular defoliation procedures. Oil contents were certainly highest for treatments $\mathrm{h}$ (leaves $>16$ ) and $\mathrm{r}$ (leaves 1-5 and $=16$ ), which are almost identical on account of loss of lower leaves. This implics that seeds produced by plants with a relative abundance of higher leaves contain more oil and accordingly less carbohydrates and protein (Shuravina, 1972). In an earlier experiment a similar weak relationship was found between oil content and leaf position.

On the whole differences in oil content between various treatments were very small and did not influence the respective values for oil yield, nor did they cause the correlation between oil yield and leaf area to differ much from that between seed yield and leaf area.

Leaf efficiency. If leaf efficiency is expressed as the ratio seed yield to leaf area, maxima are found in the treatments with relatively many young leaves (h, 1 and $r$ ). Leaf efficiency was lowest in $\mathrm{a}, \mathrm{b}, \mathrm{c}, \mathbf{i}$ and $\mathrm{k}$, where older leaves predominate. Table 1 shows data for leaf efficiency and seed and oil yields. On the whole, HS 18 gave higher yields and its leaves were more efficient. The productivity of plants defoliated early was lower than that of plants from which the leaves were removed later.

Grain weight. The effects of the various defoliation treatments on grain weight were similar to those on leaf area and on seed yield, only less marked. HS 18 seemed to be less sensitive than INRA 4701. In HS 18 seeds of plants defoliated early were lighter than those in plants from the late treatments. In INRA 4701 there was no difference between the two groups of treatments. 


\section{EFFECTS OF LEAF REMOVAL ON YIELD COMPONENTS IN SUNFLOWER}

Table 1. Yield and leaf efficiency in groups of 5 leaves.

\begin{tabular}{|c|c|c|c|c|c|c|c|}
\hline $\begin{array}{l}\text { Leaf number } \\
\text { Treatment }\end{array}$ & $\begin{array}{l}\rightarrow \\
\rightarrow\end{array}$ & $\begin{array}{l}1-5 \\
\mathrm{a}\end{array}$ & $\begin{array}{l}6-10 \\
i\end{array}$ & $\begin{array}{l}11-15 \\
k\end{array}$ & $\begin{array}{l}16-20 \\
1\end{array}$ & $\mathrm{~h}_{\mathrm{h}}^{>20}$ & $\begin{array}{l}\text { Contro } \\
\mathrm{u}\end{array}$ \\
\hline \multicolumn{8}{|l|}{ INRA 4701 (early) } \\
\hline Seed yield (g/head) & & 0.6 & - & 7.3 & 53.5 & 57.3 & 98.1 \\
\hline Oil yield (g/head) & & 0.21 & - & 2.85 & 21.51 & 25.56 & 36.35 \\
\hline \multicolumn{8}{|l|}{ Leaf efficiency } \\
\hline (mg seed $/ \mathrm{cm}^{2}$ leaf) & & 1.21 & - & 1.79 & 14.54 & 8.38 & 5.78 \\
\hline \multicolumn{8}{|l|}{ INRA 4701 (late) } \\
\hline Seed yield (g/head) & & 4.6 & 11.2 & 49.5 & 53.8 & 75.6 & 98.1 \\
\hline Oil yield (g/head) & & 1.65 & 4.12 & 19.70 & 21.84 & 29.56 & 36.35 \\
\hline \multicolumn{8}{|l|}{ Leaf efficiency } \\
\hline (mg seed $/ \mathrm{cm}^{2}$ leaf & & 8.11 & 4.51 & 9.95 & 10.32 & 13.64 & 5.78 \\
\hline \multicolumn{8}{|l|}{ HS 18 (early) } \\
\hline Seed yield (g/head) & & 1.7 & 8.4 & 37.1 & 64.1 & 40.0 & 143.1 \\
\hline Oil yield (g/head) & & 0.77 & 3.64 & 15.55 & 29.36 & 20.08 & 64.45 \\
\hline \multicolumn{8}{|l|}{ Leaf efficiency } \\
\hline (mg seed $/ \mathrm{cm}^{2}$ leaf) & & 5.25 & 3.52 & 7.86 & 16.59 & 18.87 & 10.50 \\
\hline \multicolumn{8}{|l|}{ HS 18 (late) } \\
\hline Seed yield (g/head) & & 0.3 & 22.2 & 56.4 & 70.5 & 39.0 & 143.1 \\
\hline Oil yield (g/head) & & - & 9.48 & 25.04 & 31.03 & 16.65 & 64.45 \\
\hline $\begin{array}{l}\text { Leaf efficiency } \\
\left(\mathrm{mg} \text { seed } / \mathrm{cm}^{2} \text { leaf }\right)\end{array}$ & & 8.86 & 11.08 & 13.40 & 15.36 & 15.50 & 10.50 \\
\hline
\end{tabular}

\section{Effect of halving leaf area}

Leaf area can be reduced other than by removing entire leaves. Sackston (1959) cut away a portion of every leaf with a pair of scissors and so reduced the leaf area to $50 \%$ and $25 \%$. We halved the leaf area by removing the even leaves (s) and by cutting every leaf along its midrib $(t)$. Some of the measurements are presented in Table 2. Removing even leaves (s) caused a decrease in yield of about $40 \%$ at about the same leaf efficiency as in the control. Reduction of yield in ' $t$ ' was much smaller, while leaf efficiency was about $50 \%$ higher than in the controls. That means that damage done to the leaves by, for instance, beetles, will probably do little harm as long as not more than $50 \%$ of the leaf material is affected. There was no difference in sensitivity between the two hybrids, but, as in all the other treatments, early defoliations did more harm than late defoliation.

\section{Discussion}

Most of the figures show a striking regularity. Although this is largely determined by the chosen order of the treatments, this order is not arbitrary. If it is taken into account that the younger leaves have a higher productivity than the older ones it is 
Table 2. Effect of $50 \%$ reduction in leaf area on yield parameters.

\begin{tabular}{|c|c|c|c|c|c|c|}
\hline \multirow{3}{*}{ Treatment } & \multirow{3}{*}{$\rightarrow$} & \multicolumn{2}{|l|}{$\mathrm{s}$} & \multicolumn{2}{|l|}{$\mathrm{t}$} & \multirow{3}{*}{ 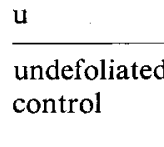 } \\
\hline & & \multicolumn{2}{|c|}{ even leaves removed } & \multicolumn{2}{|c|}{ half of each leaf removed } & \\
\hline & & early & late & early & late & \\
\hline \multicolumn{7}{|l|}{ INRA 4701} \\
\hline Leaf area $\left(\mathrm{cm}^{2}\right)$ & & 9850 & 9370 & 9230 & 12325 & 17000 \\
\hline Seed yield (g/head) & & 53.7 & 62.8 & 88.2 & 101.0 & 98.1 \\
\hline 1000 -grain weight $(\mathrm{g})$ & & 62.0 & 59.9 & 64.8 & 70.6 & 83.9 \\
\hline Oil yield $(\mathrm{g} / \mathrm{head})$ & & 18.3 & 23.0 & 32.6 & 36.6 & 36.4 \\
\hline \multicolumn{7}{|l|}{ Leaf efficiency } \\
\hline (mg seed $/ \mathrm{cm}^{2}$ leaf) & & 5.45 & 6.70 & 9.56 & 8.20 & 5.78 \\
\hline \multicolumn{7}{|l|}{$H S 18$} \\
\hline Leaf area $\left(\mathrm{cm}^{2}\right)$ & & 7900 & - & 6650 & - & 13630 \\
\hline Seed yield (g/head) & & 74.1 & 93.0 & 118.6 & 134.5 & 143.1 \\
\hline 1000 grain weight (g) & & 77.1 & 83.2 & 88.4 & 81.7 & 89.5 \\
\hline Oil yield (g/head) & & 31.8 & 46.5 & 52.7 & 58.9 & 64.5 \\
\hline \multicolumn{7}{|l|}{ Leaf efficiency } \\
\hline (mg seed $/ \mathrm{cm}^{2}$ leaf) & & 9.38 & $13.66^{*}$ & 17.84 & $19.73^{*}$ & 10.50 \\
\hline
\end{tabular}

* Converted to leaf areas of untreated control.

quite understandable that the maxima and minima for leaf area, head diameter, seed yield and grain weight coincide.

Yield in terms of seed weight per head, oil weight per head and grain weight was higher in HS 18 than in INRA 4701, although the individual plants are shorter and their leaf area smaller. As a result leaf efficiency is about twice as high in HS 18 . This agrees fairly well with the results of Shulgin \& Klimov (1974) who investigated physiological properties of long-stemmed and short-stemmed sunflowers. They found that the short-stemmed forms were characterized by a better distribution of assimilates throughout the organs and a more active photosynthetic apparatus.

The relative sensitivity of the two hybrids to defoliation is summarized in Table 3 ,

Table 3. Effect of defoliation on growth and yield parameters (means of 19 treatments, as percentages of untreated controls).

\begin{tabular}{|c|c|c|c|c|}
\hline \multirow{2}{*}{$\begin{array}{l}\text { Hybrid } \rightarrow \\
\text { Stage of defoliation } \rightarrow\end{array}$} & \multicolumn{2}{|c|}{ INRA 4701} & \multicolumn{2}{|l|}{ HS 18} \\
\hline & early & late & early & late \\
\hline Plant height & 90.7 & 96.0 & 103.5 & - \\
\hline Head diameter & 67.1 & 72.3 & 74.7 & 78.1 \\
\hline Faulty seed setting* & 7690 & 5818 & 1253 & 1627 \\
\hline Seed yield & 52.5 & 72.1 & 51.5 & 58.9 \\
\hline Oil yield & 57.9 & 72.7 & 50.5 & 58.1 \\
\hline Grain weight & 71.7 & 74.3 & 72.8 & 90.3 \\
\hline
\end{tabular}

* Area of faulty seed setting/ total head area. 
in which the averages of growth and yield parameters for the 19 defoliation treatments are expressed in percentages of those for the controls. INRA 4701 is more sensitive as regards plant height, head diameter, grain weight and seed setting in the central area of the head. The latter is explained by the very low value for this parameter in the INRA controls (0.06). As noted earlier, the central area was consistently larger for HS 18 , both in controls and treatments. HS 18 is more sensitive as regards seed yield and oil yield, which may be interpreted in terms of turnover.

Early defoliations were more harmful than late ones for almost all parameters; the only exception was the area of the central part of the head in HS 18. These results seem to confirm our thesis that the importance of the leaves for yield is not restricted to the maturation period but that it dates from an earlier stage. Chester, as cited by Sackston (1959), has stated that loss in yield is greatest when plants are defoliated in mid-season and progressively less with earlier and later defoliations.

Gonzáles de Schelotto (1974) carried out partly comparable experiments with an early and a late hybrid. She reduced leaf area by $20,40,60,80$ and $100 \%$ by punching or cutting smaller or lager pieces from every leaf, or by removing all the leaves, 1) at the bud stage, 2) at anthesis and 3) in the ripening period. Defoliation during the third period had the most adverse effect on seed yield and oil content. Sackston (1959) who defoliated at the seedling, flowering and maturing stages found that the treatment was most injurious when carried out in the flowering stage.

Both González de Schelotto and Sackston removed all the leaves at the same time, whereas in our early treatments leaves were removed one by one during the entire growth period which is more harmful to the plant in the long run. Gonzalez de Schelotto found that yield of the late hybrid was less adversely affected than that of the early hybrid. This agrees with our observations in as much as HS 18 is a little earlier than INRA 4701.

Both González de Schelotto and Sackston noted that only with complete defoliation was the oil content of the seed significantly decreased. Complete defoliation formed no part of our set of treatments; in treatment a, in which only $2-3 \%$ of leaf area was left, the oil content of the few seeds that were harvested was not lower than average, whereas in treatments $\mathrm{h}$ and $\mathrm{r}$ (only uppermost leaves) oil content increased by about $10 \%$.

\section{References}

Allison, J. C. S. \& D. J. Watson, 1966. The production and distribution of dry matter in maize after flowering. Ann. Bot. N.S. 30: 365-381.

Dantuma, G. \& M. F. Faure, 1973. Mogelijkheden van de zonnebloem in de Nederlandse landbouw. Landbouwk. Tijdschr. 85: 143-146.

Faure, M. F., 1975. Temperature and rainfall at Unilever Research Duiven in 1974. Internal report.

González de Schelotto, A. L., 1974. Efectos de la defoliacion no natural sobre el rendimiento de girasol. Personal communication.

Rodrigues Pereira, A. S., 1974. Effects of artificial defoliation on components of yield in sunflower. Proc. 6th int. Sunflower Conf. (Bucharest, Rumania) 181-188.

Rodrigues Pereira, A. S., 1977. Determination of leaf-area coefficient in sunflower. Neth. J. agric. Sci. 25: 238-242. 
Sackston, W. E., 1959. Effects of artificial defoliation on sunflowers. Can. J. Pl. Sci. 39: 108-118. Shulgin, I. A. \& S. V. Klimov, 1974. Physiological characteristics of long-stemmed and shortstemmed forms of sunflower. Soviet Pl. Physiol. 21 (5): 739-744.

Shuravina, L. G., 1972. Effect of intervarietal and varietal linear crosses on chemical composition of the seeds of sunflower $\mathrm{F}_{1}$ hybrids. Trudy Prikl. Bot. Genet. Selek. 48 (1): 168-176.

Stickler, F. C. \& A. W. Pauli, 1961. Leaf removal in grain sorghum. I. Effects of certain defoliation treatments on yield and components of yield. Agron. J. 53: 99-102. 